\title{
Enantiomeric Separations of Cationic and Neutral Compounds by Capillary Electrochromatography with $\beta$-Cyclodextrin-Bonded Charged Polyacrylamide Gels
}

\author{
Takashi KOIDE ${ }^{\dagger}$ and Kyoji Ueno \\ Chemical Analysis Laboratories, Shionogi \& Co., Ltd., \\ 12-4, Sagisu 5-Chome, Fukushima, Osaka 553-0002, Japan
}

\begin{abstract}
Keywords Enantiomeric separation, capillary electrochromatography, charged polyacrylamide gel, allyl carbamoylated $\beta$-cyclodextrin derivatives, terbutaline, propranolol, benzoin
\end{abstract}

Enantiomeric separation is one of the most important research themes in analytical chemistry, especially in the pharmaceutical field. A large number of drugs, which have one or more asymmetric centers, exist as a couple of enantiomers. Since the pharmacological activity and metabolism of two enantiomers of a certain drug may very often differ, enantioselective analytical methods are required for chiral purity control, pharmacokinetic studies and other work. During the last decade, tremendous efforts have been expended to develop enantiomeric separation methods. Important advances have been achieved with HPLC, gas chromatography and capillary electrophoresis (CE). In particular, CE is attractive because of its advantages of high efficiency, relatively short analysis time and minimal sample volume requirement.

Capillary electrochromatography (CEC), which is in essence a hybrid of HPLC and CE and is based on a fascinating new chromatographic concept ${ }^{1}$, has become increasingly popular. CEC is a powerful separation method which affords a higher theoretical plate number and superior efficiency due to its flat flow profile, compared with micro-HPLC which uses the same packing material. The separation mechanism of neutral compounds in CEC is the same as that of HPLC in principle, with separations essentially resulting from differences in the partitioning of solutes between a mobile phase and a stationary phase.

Currently, capillaries packed with the typical stationary phase for HPLC are still used in the majority of CEC studies. However, monolithic stationary phase ${ }^{2-8}$, which are ungranular polymeric separation media, are increasingly gaining attention due to their simple preparation method, wide varieties of functionalization and better stability. Very recently, the enantiomeric separation of $\mathrm{N}$-(3,5-dinitrobenzoyl)leucine diallylamide was obtained using monolithic chiral stationary phases for CEC prepared within the confines of untreat-

† To whom correspondence should be addressed. ed fused-silica capillaries by the direct copolymerization of the chiral monomer 2-hydroxyethyl methacrylate ( $N$-L-valine-3,5-dimethylanilide) carbamate with ethylene dimethacrylate, 2-acrylamido-2-methylpropanesulfonic acid and butyl or glycidyl methacrylate in the presence of a porogenic solvent. ${ }^{9}$ In our previous paper ${ }^{10}$, the enantiomeric separations of cationic and neutral compounds by CEC using a charged polyacrylamide gel as a monolithic stationary phase, in which polymeric $\beta$-cyclodextrins ( $\beta$-CD) as chiral selectors are immobilized by incorporation, were reported. Unfortunately, no enantiomeric separation was achieved using monomeric $\beta$-CD, because it was eluted out of the capillary column by electroosmotic flow (EOF) to the cathodic solution during preelectrophoresis.

In this paper, successful enantiomeric separations of cationic and neutral compounds by CEC using charged polyacrylamide gels to which allyl carbamoylated $\beta$ CD derivatives (AC- $\beta$-CD) covalently bind as monomeric $\beta$-CD are reported.

\section{Experimental}

\section{Apparatus}

CEC experiments were carried out at room temperature (approximately $25^{\circ} \mathrm{C}$ ) with a Jasco CE-800 system, which consisted of a $\pm 30 \mathrm{kV}$ high-voltage power supply (890-CE) and a UV-VIS detector (870-CE) (Japan Spectroscopic, Tokyo, Japan). A Shimadzu C-R4AX (Kyoto, Japan) was used for data collection and manipulation. The capillary temperature was not controlled during the experiments. Separations were performed with fused-silica tubing (Celect-UVT, Supelco, Bellefonte, PA, USA) of $75 \mu \mathrm{m}$ i.d. (363 $\mu$ m o.d.) filled with a charged polyacrylamide gel. Each analyte was dissolved in a solution with the same composition as that of the mobile phase, or a solution mixed with the same volume of dimethyl sulfoxide (DMSO), and was 
introduced into the anodic end of the capillary columns by electrokinetic injection. The detection wavelength was $240 \mathrm{~nm}$.

\section{Chemicals}

$N, N^{\prime}$-Methylenebisacrylamide (BIS), $N, N, N^{\prime}, N^{\prime}$ tetramethylethylendiamine (TEMED), ammonium peroxodisulfate (APS), $d i$-phosphorous pentaoxide, $\beta$-CD, benzoin, DMSO, acetic acid and distilled water were purchased from Nacalai Tesque (Kyoto, Japan). 2Acrylamido-2-methylpropanesulfonic acid (AMPS) and methacrylic acid 3-trimethoxysilylpropyl ester were obtained from Tokyo Kasei Kogyo (Tokyo, Japan). Acrylamide (AA), terbutaline, propranolol and boric acid were received from Wako (Osaka, Japan). Tris(hydroxymethyl)aminomethane (Tris) was from Sigma (St. Louis, MO, USA). Allyl isocyanate was purchased from Aldrich (Milwaukee, WI, USA). Pyridine dehydrated was obtained from Kanto Kagaku (Tokyo, Japan).

\section{Synthesis of $A C-\beta-C D$}

AC- $\beta$-CD was synthesized according to a general method $^{11,12}$ with some modifications. The method was as follows: 1) a 5-g portion of $\beta$-CD was dried in vacuo at $60^{\circ} \mathrm{C}$ for $8 \mathrm{~h}$ in the presence of $d i$-phosphorous pentaoxide; 2) the dried $\beta$-CD was dissolved in $70 \mathrm{ml}$ of dry pyridine; 3) $1 \mathrm{ml}$ of allyl isocyanate was added dropwise to the $\beta$-CD pyridine solution with stirring; 4) the reaction solution was heated at $80^{\circ} \mathrm{C}$ and kept standing for $6 \mathrm{~h}$ under a nitrogen atmosphere; 5) the reaction solution was cooled down to room temperature; 6) after pyridine was evaporated in vacuo, the raw product was purified by repeated recrystallization from acetone.

Thin-layer chromatographic separations of the product revealed the presence of $1-5$ substituted AC- $\beta$-CD and little unreacted $\beta$-CD. The formation of AC- $\beta$-CD was supported by the absorption maxima of $1706 \mathrm{~cm}^{-1}$ in the infrared spectrum.

\section{Preparation of columns}

The capillary columns for enantiomeric separations were prepared according to a method described in reference 2, with some modifications as follows. The inner surface of the capillaries was treated with a reagent mixture consisting of $40 \mu \mathrm{l}$ of methacrylic acid 3 -trimethoxysilylpropyl ester mixed with $10 \mathrm{ml}$ of 6

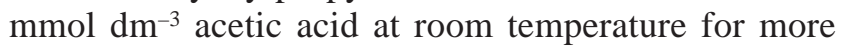
than $3 \mathrm{~h}$. After the inner surface had been thoroughly rinsed with distilled water, the capillary was filled with a mixture of 10 or $50 \mathrm{mg} \mathrm{ml}^{-1} \mathrm{AC}-\beta-\mathrm{CD}, \mathrm{AA}, \mathrm{BIS}$ and AMPS in a $100 \mathrm{mmol} \mathrm{dm}{ }^{-3}$ Tris- $150 \mathrm{mmol} \mathrm{dm}^{-3}$ boric acid buffer (pH 8.1) containing $0.5-1.0 \mathrm{mg} \mathrm{ml}^{-1}$ APS and $3 \mu \mathrm{ml}^{-1}$ TEMED with suction under reduced pressure. After the capillary had been filled, both ends were dipped into vials containing the polymerization solution, and the capillary was left standing for more than $5 \mathrm{~h}$. Finally, the capillary was set in the CE instru-

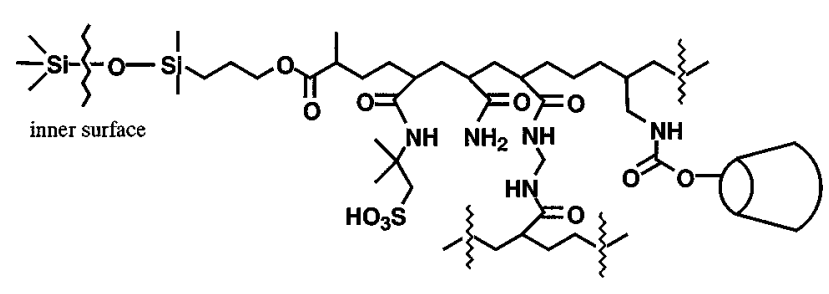

Fig. 1 Proposed schematic structure of an AC- $\beta$-CD-bonded charged polyacrylamide gel.

ment and preelectrophoresed for a few hours until the baseline of the detector output became stable.

The nomenclature introduced by Hjertén ${ }^{13}$ was used to represent the total acrylamide concentration $(\% T)$ and the degree of cross-linking $(\% C)$ :

$$
\begin{aligned}
& \% T=100(a+b+c) / V, \\
& \% C=100 b /(a+b+c),
\end{aligned}
$$

where $a, b$ and $\mathrm{c}$ are the mass of AA, BIS and AMPS (in $\mathrm{g}$ ), respectively, and $V$ is the volume (in $\mathrm{ml}$ ). In addition to these values, the mole percentage of AMPS, defined by Fujimoto 2 , was used,

$$
\% S=100 \gamma /(\alpha+\beta+\gamma) \text {, }
$$

where $\alpha, \beta$ and $\gamma$ are the molarities of AA, BIS and AMPS, respectively.

\section{Results and Discussion}

According to the procedures described in the Experimental section, AC- $\beta$-CD-bonded charged polyacrylamide gel-filled capillaries, in which EOF would be generated, were prepared. The proposed schematic structure of the gels is shown in Fig. 1. The crosslinked polyacrylamide gels bind covalently to the inner surface by a pretreatment with methacrylic acid 3trimethoxysilylpropyl ester, and AMPS and AC- $\beta$-CD are attached to the gels. The sulfo group derived from AMPS is ionized in solutions of a wide range of $\mathrm{pH}$, and permits the generation of EOF. The $\beta$-CD structure derived from $\mathrm{AC}-\beta$-CD works as a chiral selector.

First, enantiomeric separations of two cationic compounds, terbutaline and propranolol (Fig. 2, a and b), were investigated using an AC- $\beta$-CD-bonded charged polyacrylamide gel-filled capillary (AC- $\beta$-CD added to the polymerization solution, $50 \mathrm{mg} \mathrm{ml}^{-1} ; \% T, 5 ; \% C$, $10 ; \% S, 5.6)$. The enantiomeric separations of the two compounds were achieved by using $200 \mathrm{mmol} \mathrm{dm}^{-3}$ Tris-300 mmol dm${ }^{-3}$ boric acid buffer $(\mathrm{pH} \mathrm{9.0)}$ as a mobile phase based on the information in reference 10. On the other hand, a high current due to using the phosphate and borate buffers as a mobile phase caused bubble formation. The chromatograms are shown in Fig. 3 

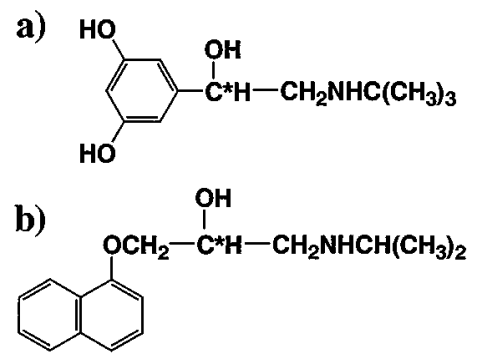

c)<smiles>O=C(c1ccccc1)C(O)c1ccccc1</smiles>

Fig. 2 Chemical structures of a) terbutaline, b) propranolol and c) benzoin.
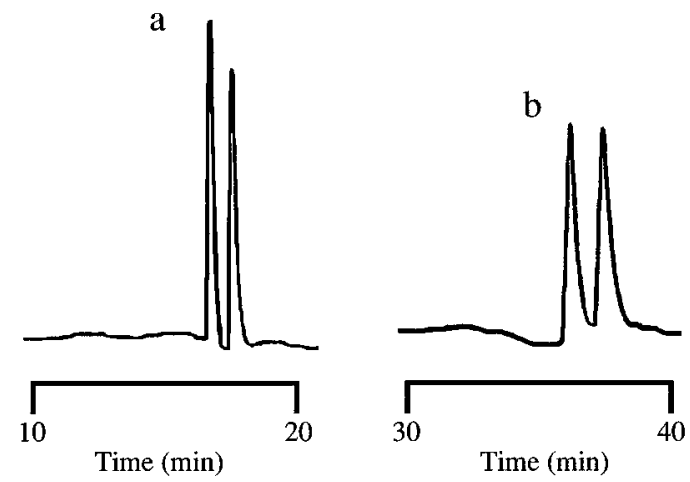

Fig. 3 Enantiomeric separations of a) terbutaline and b) propranolol. Conditions: $\% T, 5 ; \% C, 10 ; \% S, 5.6 ; \mathrm{AC}-\beta-\mathrm{CD}, 50$ $\mathrm{mg} \mathrm{ml}{ }^{-1}$; capillary, $70 \mathrm{~cm} \times 75 \mu \mathrm{m}$ i.d. (effective length, 35 $\mathrm{cm}$ ); mobile phase, $200 \mathrm{mmol} \mathrm{dm}^{-3}$ Tris-300 $\mathrm{mmol} \mathrm{dm}^{-3}$ boric acid buffer ( $\mathrm{pH} 9.0)$; detection wavelength, $240 \mathrm{~nm}$; applied voltage (current), a) $25 \mathrm{kV}(18 \mu \mathrm{A})$, b) $18 \mathrm{kV}(12 \mu \mathrm{A})$; concentration of the samples, $4 \mathrm{mmol} \mathrm{dm}^{-3}$; sample injection, electrokinetic method of a) $15 \mathrm{kV} 2 \mathrm{~s}$ and b) $3 \mathrm{kV} 2 \mathrm{~s}$.

(a: separation factor $^{14}, \alpha=1.05$; resolution ${ }^{14}, R_{\mathrm{s}}=1.86$; theoretical plate number, $N \geqq 67000 \mathrm{~m}^{-1}$. b: $\alpha=1.03$, $R_{\mathrm{s}}=1.54, N \geqq 84000 \mathrm{~m}^{-1}$ ). The EOF velocity was $1.8 \mathrm{~cm}$ $\mathrm{min}^{-1}$ taking DMSO as unretained solute marker when terbutaline was analyzed.

Second, the enantiomeric separation of a neutral compound, benzoin (Fig. 2, c), was also achieved as shown in Fig. $4\left(\alpha=1.06, R_{\mathrm{s}}=1.40, N \geqq 31000 \mathrm{~m}^{-1}\right)$ when AC- $\beta$ $\mathrm{CD}$ was used at the concentration of $10 \mathrm{mg} \mathrm{ml}^{-1}$ in the polymerization solution. The EOF velocity was $1.9 \mathrm{~cm}$ $\mathrm{min}^{-1}$ taking DMSO as unretained solute marker.

The run-to-run reproducibilities of the retention time and the separation factor were also examined for terbutaline and benzoin for the conditions shown in Figs. 3 and 4. The relative standard deviations (RSD) of the retention times were less than 0.5 and $0.9 \%$ over the course of six injections, respectively. Each RSD of the separation factor was $0.1 \%$. These satisfactory results are summarized in Table 1.

Bubble formation has often been a serious problem

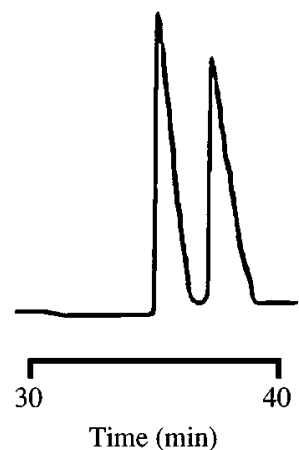

Fig. 4 Enantiomeric separation of benzoin. Conditions: AC$\beta$-CD, $10 \mathrm{mg} \mathrm{ml}^{-1}$; applied voltage (current), $25 \mathrm{kV}(28 \mu \mathrm{A})$; sample injection, electrokinetic method of $15 \mathrm{kV} 2 \mathrm{~s}$. Other conditions are the same as in Fig. 3.

Table 1 Reproducibilities of retention time and separation factor

\begin{tabular}{llcc}
\hline \multirow{2}{*}{ Compound } & \multicolumn{3}{c}{ Reproducibility (RSD, \%, n=6) } \\
\cline { 2 - 4 } & $t_{1}{ }^{\mathrm{c}}$ & $t_{2}{ }^{\mathrm{c}}$ & $\alpha$ \\
\hline Terbutaline $^{\mathrm{a}}$ & 0.4 & 0.5 & 0.1 \\
Benzoin $^{\mathrm{b}}$ & 0.9 & 0.9 & 0.1 \\
\hline
\end{tabular}

a. Conditions: applied voltage (current), $20 \mathrm{kV}(12 \mu \mathrm{A})$; other conditions are the same as Fig. 3.

b. Conditions are the same as Fig. 4.

c. $t_{1}$ is the retention time of the first eluted enantiomer and $t_{2}$ is the retention time of the antipode.

and would not be eliminated easily in capillary gel electrophoresis using a cross-linked polyacrylamide gel. Actually, we sometimes observed bubble formation during the preparation and use of $\mathrm{AC}-\beta$-CD-bonded charged polyacrylamide gel-filled capillaries in our investigation. However, we also found that the bubbles became smaller, and finally disappeared upon the application of a continuous-voltage to the columns for a while, as described in reference 4 , and rarely experienced failure in column preparation. Thus, chiral selector-bonded charged polyacrylamide gel-filled capillaries would offer great promise as a new method for enantiomeric separations by CEC.

In conclusion, we studied enantiomeric separation by CEC and achieved the separations of racemic terbutaline, propranolol and benzoin using capillaries filled with $\mathrm{AC}-\beta$-CD-bonded charged polyacrylamide gels

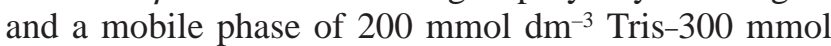
$\mathrm{dm}^{-3}$ boric acid buffer ( $\mathrm{pH} 9.0$ ). The run-to-run reproducibilities of the retention time and the separation factor were also examined for terbutaline and benzoin, and were found to be satisfactory. The day-to-day reproducibility, column-to-column reproducibility and the stability of the columns are under investigation.

At present, the enantiomeric separation of various compounds and the preparation of cationic charged gel- 
filled capillaries, in which reversed EOF would be generated, for enantiomeric separations of anionic and neutral compounds are being examined.

\section{References}

1. L. A. Colón, Y. Guo and A. Fermier, Anal. Chem., 69, 461A (1997).

2. C. Fujimoto, Anal. Chem., 67, 2050 (1995).

3. C. Fujimoto, J. Kino and H. Sawada, J. Chromatogr. A, 716, 107 (1995).

4. C. Fujimoto, Y. Fujise and E. Matsuzawa, Anal. Chem., 68, 2753 (1996).

5. A. Palm and M. V. Novotny, Anal. Chem., 69, 4499 (1997).

6. E. C. Peters, M. Petro, F. Svec and J. M. J. Fréchet, Anal.
Chem., 70, 2288 (1998).

7. E. C. Peters, M. Petro, F. Svec and J. M. J. Fréchet, Anal. Chem., 70, 2296 (1998).

8. G. Wulff, Angew. Chem. Int. Ed. Engl., 34, 1812 (1995).

9. E. C. Peters, K. Lewandowski, M. Petro, F. Svec and J. M. J. Fréchet, Anal. Commun., 35, 83 (1998).

10. T. Koide and K. Ueno, Anal. Sci., 14, 1021 (1998).

11. I. D. Cruzado, G. Vigh, J. Chromatogr., 608, 421 (1992).

12. K. Fujimura, S. Suzuki, K. Hayashi and S. Masuda, Anal. Chem., 62, 2198 (1990).

13. S. Hjertén, Arch. Biochem. Biophys., Suppl. 1, 147 (1962).

14. R. Kuhn, J. Wagner, Y. Walbroehl and T. Bereuter, Electrophoresis, 15, 828 (1994).

(Received March 5, 1999) (Accepted May 18, 1999) 